\title{
Shuxuening injection protects against myocardial ischemia- reperfusion injury through reducing oxidative stress, inflammation and thrombosis
}

\author{
Ruiying Wang ${ }^{1,2,3,4 \#}$, Min Wang ${ }^{1,2,3,4 \#}$, Jiahui Zhou ${ }^{1,2,3,4}$, Tianyuan $\mathrm{Ye}^{1,2,3,4}$, Xueheng Xie ${ }^{5}$, Dong $\mathrm{Ni}^{6}$, Jingxue \\ Ye $^{1,2,3,4}$, Qiaoling $\mathrm{Han}^{7}$, Caixia Di ${ }^{7}$, Liang Guo ${ }^{7}$, Guibo Sun ${ }^{1,2,3,4}$, Xiaobo Sun ${ }^{1,2,3,4}$
}

${ }^{1}$ Key Laboratory of New Drug Discovery Based on Classic Chinese Medicine Prescription, Beijing 100193, China; ${ }^{2}$ Beijing Key Laboratory of Innovative Drug Discovery of Traditional Chinese Medicine (Natural Medicine) and Translational Medicine, Beijing 100193, China; ${ }^{3}$ Key Laboratory of Bioactive Substances and Resource Utilization of Chinese Herbal Medicine, Ministry of Education, Beijing 100193, China; ${ }^{4}$ Institute of Medicinal Plant Development, Peking Union Medical College and Chinese Academy of Medical Sciences, Beijing 100193, China; ${ }^{5}$ Harbin

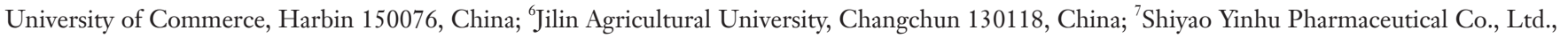
Yuncheng 044000, China

Contributions: (I) Conception and design: G Sun, X Sun, M Wang; (II) Administrative support: G Sun, X Sun; (III) Provision of study materials or patients: C Di, Q Han, L Guo; (IV) Collection and assembly of data: R Wang, M Wang, J Zhou, X Xie, D Ni; (V) Data analysis and interpretation: R Wang, M Wang, J Zhou; (VI) Manuscript writing: All authors; (VII) Final approval of manuscript: All authors.

\#These authors contributed equally to this work.

Correspondence to: Guibo Sun; Xiaobo Sun. Institute of Medicinal Plant Development, Chinese Academy of Medical Sciences and Peking Union Medical College, No. 151, Malianwa North Road, Haidian District, Beijing 100193, China. Email: sunguibo@126.com; sun_xiaobo163@163.com.

Background: Shuxuening injection (SXNI) has a good effect on cardiovascular and cerebrovascular diseases. Here, our study aims to investigate whether SXNI have the protective effect on myocardial ischemia-reperfusion injury (MIRI) and elucidate the mechanism of SXNI's cardiac protection.

Methods: In this experiment, the coronary arteries of Sprague-Dawley (SD) rats were ligated for the induction of a MIRI model. TTC staining and haematoxylin-eosin (HE), as well as troponin I (TnI), lactate dehydrogenase (LDH), aspartate aminotransferase (AST), creatine kinase (CK) and CK-MB levels, were used to detect the protective effect of SXNI. In rat cardiac tissue, superoxide dismutase, catalase, glutathione and malondialdehyde (MDA) activities and glucose-regulated protein 78 (GRP78), calreticulin (CRT), CCAAT/ enhancer binding protein homologous protein (CHOP) and caspase-12 expression levels were detected. In rat serum, the levels of inflammatory factors, including high-sensitivity C-reactive protein, monocyte chemoattractant protein-1, tumour necrosis factor- $\alpha$, interleukin-6 (IL-6) and IL-1 $\beta$, were measured by Elisa. In the rat arterial tissue, Toll-like receptor 4 (TLR4)/nuclear factor kappa B (NF-кB) expression was measured by western blot. In the rat plasma, ELISA was used to assay the levels of coagulation and plasmin system indicators, including platelet activating factor, endothelin, tissue factor (TF), plasminogen inhibitor, thromboxane B2, plasma fibrinogen.

Results: The results showed that SXNI can reduce the infarct size of myocardial tissue, decrease the myocardial enzyme and TnI levels and decrease the degree of myocardial damage compared with the model group. Additionally, SXNI can increase the activity of antioxidant enzymes, reduce the MDA level and decrease the GRP78, CRT, CHOP and caspase-12 expression levels. SXNI also decreased the levels of inflammatory cytokines in rat serum, lowered the level of procoagulant molecules in plasma and reduced the TLR4/NF-кB expression.

Conclusions: SXNI has protective effect on MIRI mainly by inhibiting oxidative stress and endoplasmic reticulum stress (ERS), thereby regulating TLR4/NF- $\kappa B$ pathway to reduce inflammation, and lowing procoagulant-related factors levels to reduce the risk of thrombosis. 
Keywords: Shuxuening injection (SXNI); oxidative stress; endoplasmic reticulum stress (ERS); inflammation; thrombosis

Submitted Jul 04, 2019. Accepted for publication Aug 26, 2019.

doi: $10.21037 /$ atm.2019.09.40

View this article at: http://dx.doi.org/10.21037/atm.2019.09.40

\section{Introduction}

Ischemic heart disease is the leading cause of death in humans. Clinically, early successful recovery of myocardial blood flow is the most effective way to improve clinical outcomes (1). However, the process of reperfusion can also cause damage, the phenomenon known as myocardial ischemia reperfusion (IR) injury (MIRI) (2). MIRI is characterized by decreased systolic and diastolic function, arrhythmia, myocardial energy metabolism disorder, ultrastructural changes and no-reflow of blood vessels in the ischemic myocardium after reperfusion. The mechanism of MIRI has not yet been fully illuminated (3). Energy metabolism disorder, massive production of free radicals, intracellular calcium overload, myocardial apoptosis and endothelial cell dysfunction are the basis of MIRI (4).

When tissue cells are ischemic and hypoxic, the function of oxygen free radical (OFR) scavenging system is reduced or lost, but its production system is enhanced. Once the blood supply and oxygen supply of the tissue are restored, the OFR is produced and rapidly stacked (5). The damage of the large amounts of free radicals produced during perfusion is mainly manifested by lipid peroxidation. During myocardial IR, endothelial cells not only produce large amounts of reactive oxygen species (ROS) but also significantly reduce antioxidant activity. The production of endothelin (ET) after myocardial IR is increased, thereby resulting in the strong contraction of blood vessels and a large accumulation of platelets which aggravate cardiomyocyte damage $(6,7)$.

Shuxuening injection (SXNI) is an extract of Ginkgo biloba, and its active ingredients are mainly flavonoids, ginkgolides and bilobalide. SXNI is clinically used in treating coronary heart disease, angina, cerebral embolism and cerebral vasospasm (8). Recent advances in pharmacological studies on SXNI showed that its ingredients can improve endothelial injury, increase cerebral blood flow, scavenge free radical, reduce platelet adhesion rate and enhance cellular immune activity. Clinical trials have also shown that the addition of SXNI in the treatment of coronary heart disease with angina is better, safer and less toxic than nitroglycerin alone. SXNI contains a variety of active ingredients, which mainly include flavonoid glycosides and ginkgolides that have synergistic and reduce side effects compared with single-agent drugs. SXNI can significantly improve the clinical symptoms and cardiac function of patients with left ventricular diastolic dysfunction in coronary heart disease $(9,10)$.

The mechanism of MIRI production is relatively complicated. Drugs with a single target generally cannot exert better effects, and have some side effects. Traditional Chinese medicine (TCM) has the features of multicomponent and multi-target. Thus, TCM has advantages in the treatment of MIRI $(11,12)$. Therefore, in our article, we aimed to investigate the protection of SXNI on MIRI and explore the protective mechanism of SXNI from the aspects of anti-oxidation, anti-endoplasmic reticulum stress (ERS), anti-inflammatory and anti-platelet aggregation. Our research will provide experimental basis for improving the clinical value of SXNI, excavating the characteristics and highlights of SXNI and expanding the market share of SXNI.

\section{Methods}

\section{Drugs}

SXNI (drug approval no. Z1421945, batch no. 1041706153) was provided by China Shiyao Yinhu Pharmaceutical Co., Ltd. (Yuncheng, China). The chemical content of one injection (5 mL/unit) containing $4.2 \mathrm{mg}$ total Ginkgo flavonol glycosides and $0.7 \mathrm{mg}$ Ginkgolides, is equal to $17.5 \mathrm{mg}$ G. biloba leaf extract according to manufacturer's instruction. Nitroglycerin injection (drug approval no. H11020289, batch no. 20171220) was obtained by Beijing Yimin Pharmaceutical Co., Ltd. (Beijing, China). Ginkgolide injection (drug approval no. Z20110035, batch no. 08170919) was obtained by Chengdu Baiyu 
Pharmaceutical Co., Ltd. (Chengdu, China).

\section{Animals}

Adult male Sprague-Dawley (SD) rats weighing 230-270 g (Beijing Vital River Laboratory Animal Technology Co., Ltd., Beijing, China) were obtained. Our research was approved by the Laboratory Animal Ethics Committee of the Institute of Medicinal Plant Development, Peking Union Medical College and complied with NIH Guidelines for the Care and Use of Laboratory Animals. All animals were randomized into seven groups, as followed: sham group ( $\mathrm{n}=18)$; Ischemia reperfusion (IR) group $(\mathrm{n}=17)$; IR + SXNI (4.38, 8.75, $17.5 \mathrm{mg} / \mathrm{kg}, \mathrm{n}=16,17,15)$ group; IR + Nitroglycerin $(0.3 \mathrm{mg} / \mathrm{kg}, \mathrm{n}=15)$. SXNI and Ginkgolide were administrated by intraperitoneal injection for 3 days, and the same amount of $0.9 \%$ saline were administrated to sham and I/R groups for 3 days. Nitroglycerin were administrated by tail intravenous injection $1 \mathrm{~h}$ before surgery.

\section{MIRI model}

Rats were anesthetized by intraperitoneally injecting chloral hydrate solution $(100 \mathrm{mg} / \mathrm{kg})$. Electrocardiogram was recorded, and a small animal ventilator was connected with a tidal volume of $15 \mathrm{~mL} / \mathrm{kg}$ and a respiratory rate of 70 times/min. The left anterior descending of the coronary artery was tied with $6-0$ suture over a tube at a depth of about $1.5-2 \mathrm{~mm}$ and a width of $3-4 \mathrm{~mm}$. The continuous elevation of the ST segment and paleness of the blood myocardium at the far end of the ligation point indicated successful myocardial ischemia model (13). After $30 \mathrm{~min}$, the ligation line was removed, and reperfusion lasted for $24 \mathrm{~h}$. The ST segment decreased and the ischemic pale myocardium became ruddy. The ST segment and ischemic pale myocardium were taken as the indicators of the success of the reperfusion model. The sham group underwent same operation with the I/R model, except not blocking the left anterior descending branch of the coronary artery.

\section{Myocardial infarct size determination}

After MIRI model, the hearts were taken out and flushed with $0.9 \%$ saline. Then, the samples were frozen $-80{ }^{\circ} \mathrm{C}$ for $8 \mathrm{~min}$ and crosscut into approximately $2 \mathrm{~mm}$ wafer along the direction of ligature. The slices were placed into $1 \%$ of the TTC solution in $37^{\circ} \mathrm{C}$ water bath for $12 \mathrm{~min}$ and fixed in tissue fixative overnight. Image Pro plus 5.0 software was used to calculate the infarct area after the images were taken by using a high-resolution camera $(14,15)$. The degree of myocardial injury was expressed by infarct area/left ventricular area $\times 100 \%$.

\section{Hematoxylin-eosin (HE) staining assessment}

After MIRI model, the hearts were left and rinsed off the blood, and immediately fixed in tissue fixative for at least $48 \mathrm{~h}$. Afterwards, the heart samples were dehydrated in different concentration of ethanol successively and embedded in paraffin max. Then paraffin block was cut into slices and stained with HE. The images of slices were obtained using IncuCyte ${ }^{\mathrm{TM}}$ S3 ZOOM cell imaging system (Essen BioScience, Ann Arbor, MI).

\section{Immunobistochemical assessment}

Troponin I (TnI) expression in rat ventricular myocardium was detected by immunohistochemistry. Tissue sections of paraffin embedded tissue specimens were deparaffinized with xylene and stained to determine the expressions of TnI. Then, the images of slices were obtained using IncuCyte ${ }^{\mathrm{TM}}$ S3 ZOOM cell imaging system (Essen BioScience, Ann Arbor, MI).

Determination of lactate debydrogenase (LDH), aspartate aminotransferase (AST), creatine kinase (CK), CK-MB and TnI levels in rat serum

After MIRI model, blood samples were collected by abdominal aortic blood collection and centrifuged at 3,600 rpm for $10 \mathrm{~min}$. The serum was received for the detection of LDH, AST, CK, CK-MB and TnI using kits (Beyotime Biotechnology, Shanghai, China). Detailed instructions are introduced in the manual. Three independent experiments at least were conducted.

\section{Malondialdebyde (MDA), SOD, catalase (CAT) and glutathione (GSH) levels of rat cardiac tissue determination}

After the MIRI model, heart tissues were removed, and then crushed and mixed using $0.9 \%$ saline $(10 \% \mathrm{w} / \mathrm{v})$. The suspension was centrifuged at 3,600 rpm for $10 \mathrm{~min}$. The supernatant was received and used for testing the activities of SOD, CAT and GSH-Px, the ratio of total GSH and 
oxidized glutathione (GSSG), and level of MDA in heart tissue using kits (Beyotime Biotechnology, Shanghai, China). Detailed instructions are introduced in the manual. At least three independent experiments were conducted.

\section{Inflammatory factors of rat serum determination}

Rat serum was reserved to determine tumor necrosis factor- $\alpha$ (TNF- $\alpha$ ), interleukin-6 (IL-6), IL-1 $\beta$, highsensitivity C-reactive protein (hs-CRP) and monocyte chemoattractant protein-1 (MCP-1) levels using Elisa kit (Beijing Expandbiotech Ltd., Beijing, China). The experimental steps are as follows. Firstly, the samples were added into 96-well plate from ELISA kit and incubated in $37^{\circ} \mathrm{C}$ for $30 \mathrm{~min}$. Then, the plate was wash 5 times using liquid detergent and placed at $37^{\circ} \mathrm{C}$ for $30 \mathrm{~min}$ after adding enzyme reagent. The plate was washed again five times, and then chromogenic agent was added at $37^{\circ} \mathrm{C}$ in the dark for $15 \mathrm{~min}$. At last, the termination solution was added and the absorbance was measured at $450 \mathrm{~nm}$. The concentration of each index was obtained by the standard curve. At least three independent experiments were conducted.

\section{Plasma coagulation and fibrinolytic enzyme system indicators determination}

After MIRI model, blood samples were collected in anticoagulant tubes and centrifuged at 3,600 rpm for $10 \mathrm{~min}$. The supernatant was left for ET, platelet activating factor (PAF), plasminogen activator inhibitor 1 (PAI-1), tissue factor (TF), thromboxane B2 (TXB2) and plasma fibrinogen ( $\mathrm{Fbg}$ ) detection using ELISA kit (Beijing Expandbiotech Ltd., Beijing, China). The experimental procedure is the same as above. At least three independent experiments were conducted.

\section{Western blot analysis}

The method was described in reported articles $(16,17)$. Primary antibodies including glucose-regulated protein 78 (GRP78, sc-13539), calreticulin (CRT, sc-101436), CCAAT/enhancer binding protein homologous protein (CHOP, sc-71136), caspase-12 (sc-21747), Toll-like receptor 4 (TLR4, sc-293072) and nuclear factor kappa B (NF- $\kappa$ B, sc-166588), were bought from Santa Cruz Biotechnology (Dallas, USA). The densitometric analysis of the bands was conducted using the Gel Pro software
(Media Cybernetics, Rockville, MD, USA). At least three independent experiments were conducted.

\section{Statistical analysis}

The data were expressed as mean \pm standard deviation $(\mathrm{SD})$ and analyzed by one-way ANOVA followed by Tukey's test with GraphPad Prism 5.0 software (SPAA Inc., Chicago, IL, USA), and the graphical presentation of data was also undertaken with GraphPad Prism. $\mathrm{P}<0.05$ was considered statistically significant.

\section{Results}

\section{Protective effect of SXNI on MIRI-induced beart damage}

TTC staining was used to measure the myocardial infarct size (18). The results showed in Figure 1 indicated that the infarct area of the IR group reached up to $35 \%$. SXNI $(8.75$ and $17.5 \mathrm{mg} / \mathrm{kg}$ ) treatment before IR reduced infarct size $(16 \%$ and $17 \%)$ significantly. Ginkgolide $(5 \mathrm{mg} / \mathrm{kg})$ and Nitroglycerin $(0.3 \mathrm{mg} / \mathrm{kg})$ didn't improve myocardial significantly. HE staining showed the pathological change in myocardial tissue. In the IR model group, myofibril loss, myocardial cell necrosis and structural abnormalities were observed, thereby indicating severe cardiac injury. SXNI group can reduce pathological damage of rat heart to some extent, as showed in Figure 2.

The myocardial enzymes (LDH, AST, CK, CK-MB) and TnI levels were also important indicators to measure the degree of myocardial injury (19). As showed in Figure 3A,B, immunohistochemistry results showed that $\mathrm{TnI}$ expression had significant reduction or loss in the area of myocardial infarction and TnI expression gradually increases with increasing dose of SXNI, which proved SXNI can reduce myocardial infarction area. It's obvious that the levels of LDH, AST, CK, CK-MB and TnI had a sharp rise after myocardial IR. SXNI $(4.375,8.75,17.5 \mathrm{mg} / \mathrm{kg})$ can reduce AST, LDH and TnI levels dose-dependently. The CK level decreased significantly in the IR+ SXNI $(17.5 \mathrm{mg} / \mathrm{kg})$ group, and the CK-MB level decreased in the IR+ SXNI (8.75, $17.5 \mathrm{mg} / \mathrm{kg})$ group. Nitroglycerin $(0.3 \mathrm{mg} / \mathrm{kg})$ effectively decreased the myocardial enzymes and TnI levels, but the IR + Ginkgolide (5 mg/kg) group only decreased the TnI level, as showed in Figure 3C,D,E,F,G. The results above showed that SXNI played an extremely important role in cardioprotection against MIRI. 
A

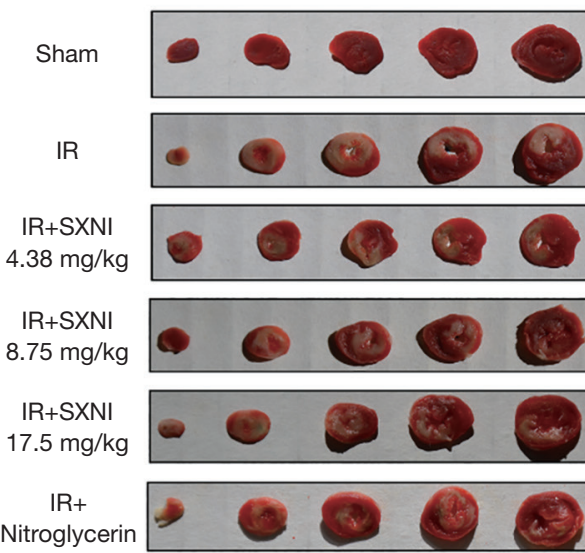

B

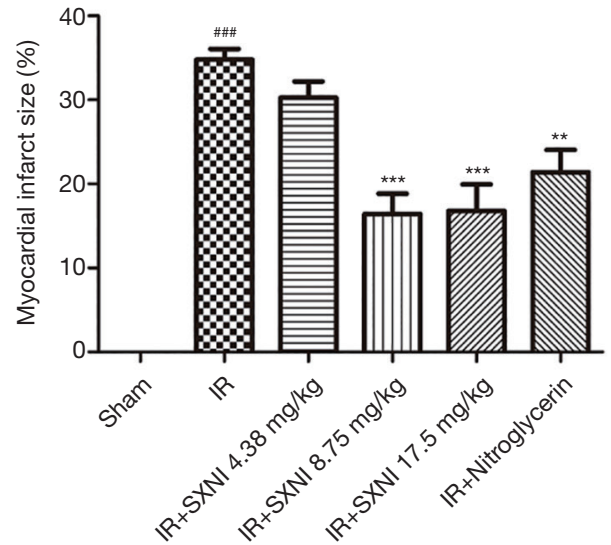

C

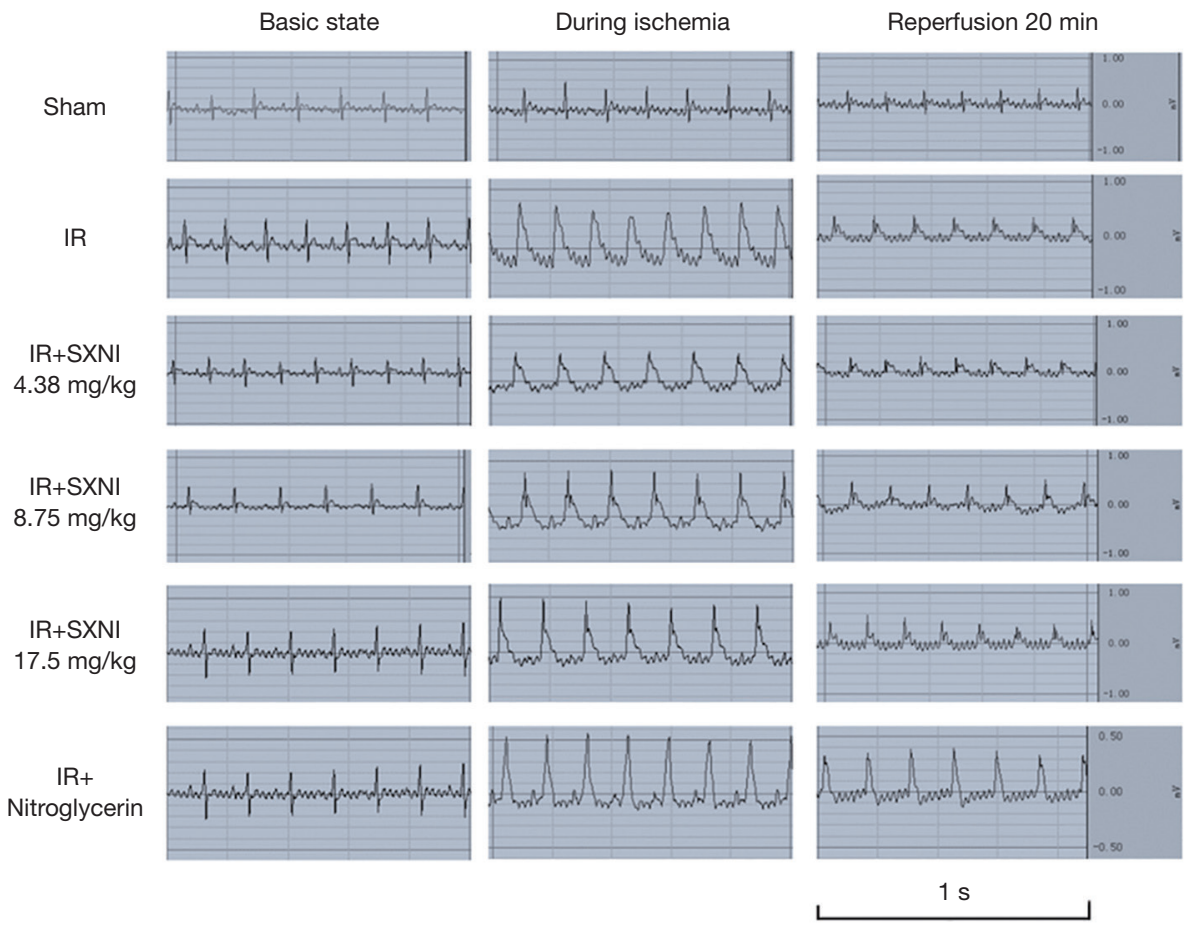

Figure 1 SXNI can reduce myocardial infarct size after MIRI. (A) Red areas stained by TTC represented undamaged tissue and unstained pale areas indicated infarcted tissue; (B) infarct area was expressed as the percentage of total area; (C) electrocardiogram at different time point (i.e., basic state, during ischemia, and reperfusion $20 \mathrm{~min}$ ). Data are expressed as the means $\pm \mathrm{SD}$ from at least three independent

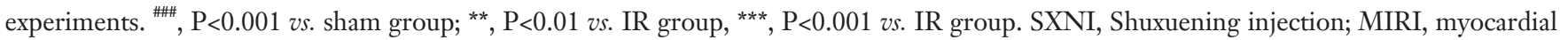
ischemia-reperfusion injury.

\section{Effect of SXNI on oxidative stress}

GSH, CAT, and SOD are three primary antioxidant enzymes and MDA reflects the level of lipid peroxide (20). And the ratio of GSH to GSSG is also a good measure of oxidative stress (21). As shown in Figure 4, the IR injury model group reduced the activity of the three enzymes
$(\mathrm{P}<0.01)$ and the ratio of total GSH and GSSG, and increased the level of MDA significantly $(\mathrm{P}<0.01)$, indicating that oxidative stress is involved in MIRI. However, SXNI $(8.75,17.5 \mathrm{mg} / \mathrm{kg})$ can increase the activity of antioxidant enzyme, GSH and reduce the MDA level in different degrees. A total of $17.5 \mathrm{mg} / \mathrm{kg}$ SXNI can reactivated CAT. 
Sham

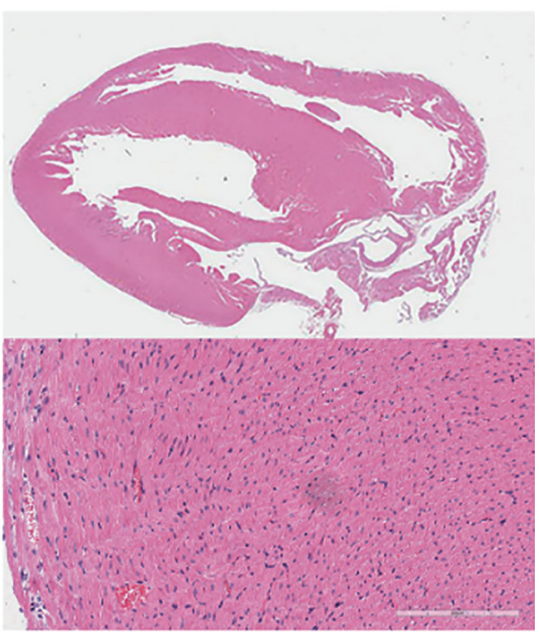

IR+SXNI $8.75 \mathrm{mg} / \mathrm{kg}$

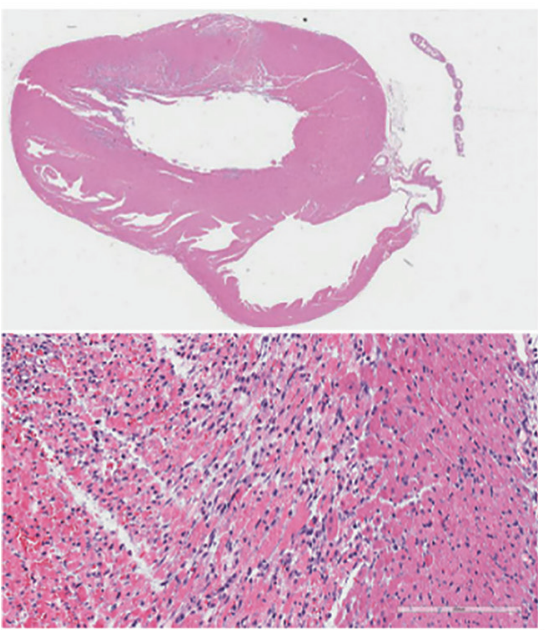

IR

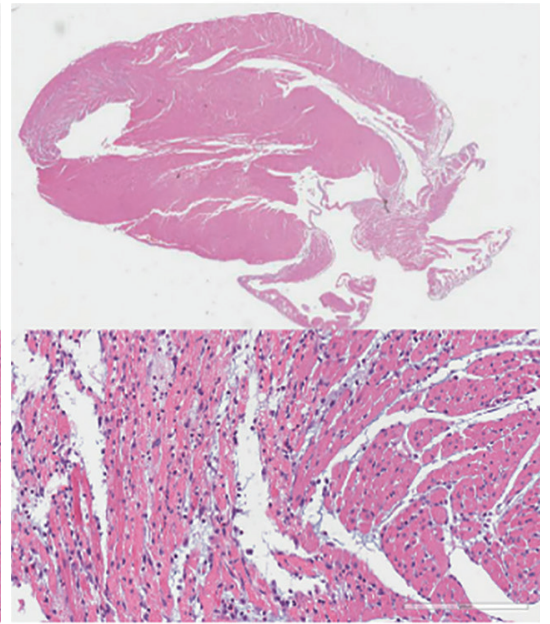

IR+SXNI $17.5 \mathrm{mg} / \mathrm{kg}$

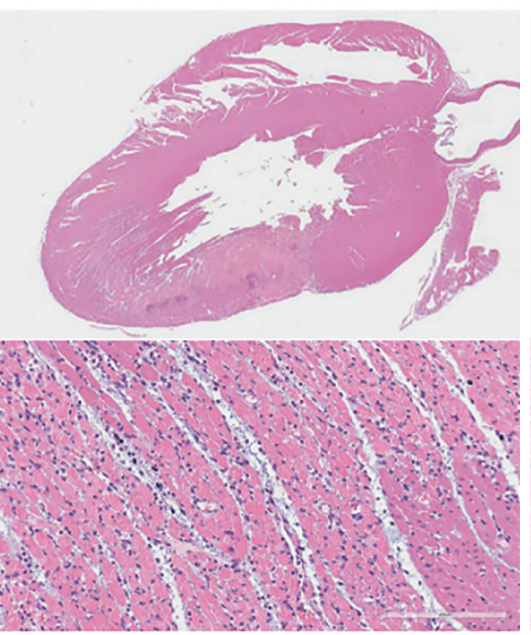

IR+SXNI $4.38 \mathrm{mg} / \mathrm{kg}$

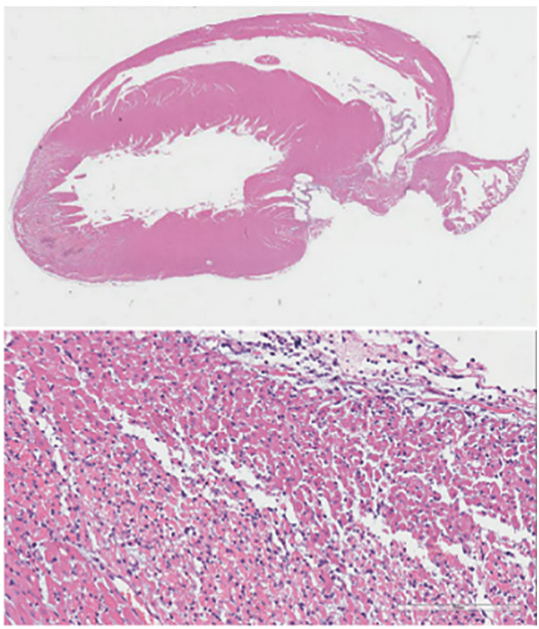

IR+Nitroglycerin

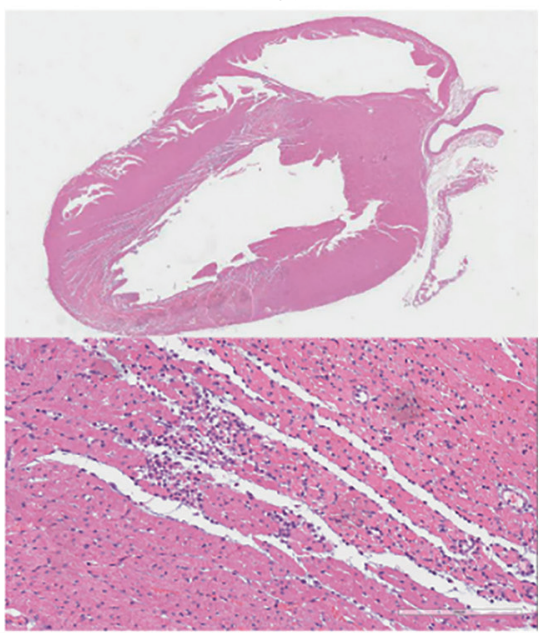

Figure 2 SXNI can ameliorate cardiac pathological damage induced by MIRI. HE staining was presented through a heart panorama picture and a left ventricular myocardial tissue image (scale bar, $200 \mu \mathrm{m}$ ). SXNI, Shuxuening injection; MIRI, myocardial ischemia-reperfusion injury

SOD activity was improved by SXNI dose-dependently. SXNI may have certain inhibitory effect on oxidative stress.

\section{Effect of SXNI on ERS}

As shown in Figure 5, the Glucose Regulated Protein 78 (GRP78), CHOP, caspase-12 and CRT expression levels in rat myocardial tissue were determined by western blot. The results proved that GRP78, CHOP, caspase-12 and CRT expression levels increased in the model group, thereby indicating that ERS aggravates MIRI (22). The GRP78, CHOP, caspase-12 and CRT expression levels decreased after administrating SXNI. In particular, the high dose of SXNI $(17.5 \mathrm{mg} / \mathrm{kg})$ had significant regulatory effects for MIRI.

\section{Effect of SXNI on inflammatory}

The TNF- $\alpha$, IL-6, IL-1 $\beta$, hs-CRP and MCP-1 levels in serum were detected using ELISA method. The results of Figure $6 A$ showed that the level of inflammation-related factors (i.e., TNF- $\alpha$, IL-6, IL-1 $\beta$, hs-CRP and MCP-1) in rat serum was significantly increased $(\mathrm{P}<0.01)$ in the IR group. SXNI could reduce the levels of inflammatory factors dose-dependently $(\mathrm{P}<0.01)$.

The protein expression in the rat arterial tissue was 
A

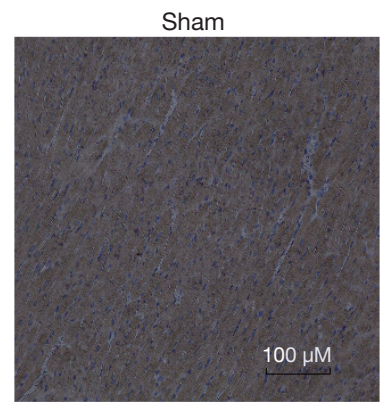

IR+SXNI $8.75 \mathrm{mg} / \mathrm{kg}$

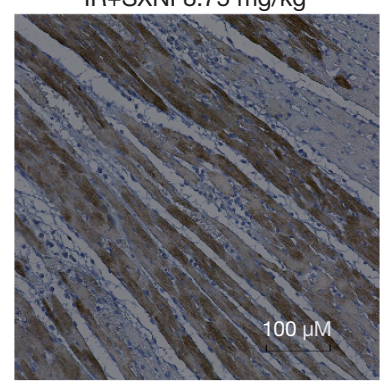

B

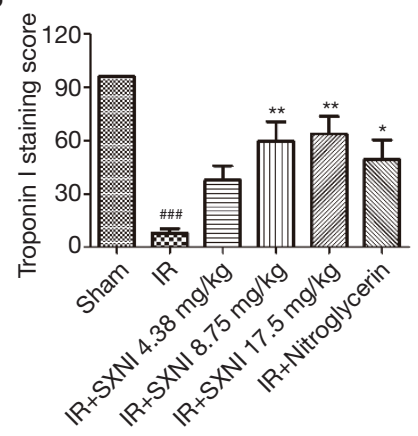

E

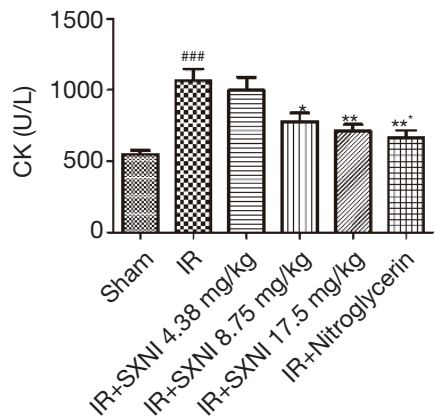

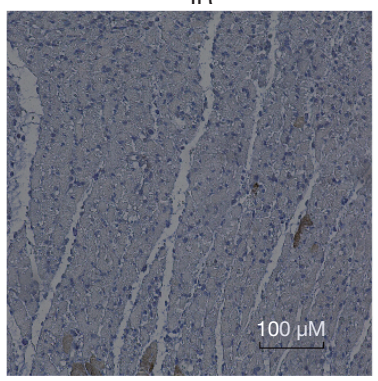

IR+SXNI $17.5 \mathrm{mg} / \mathrm{kg}$

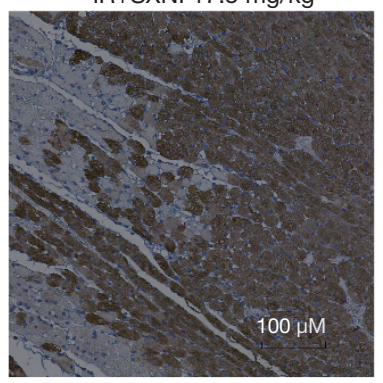

C
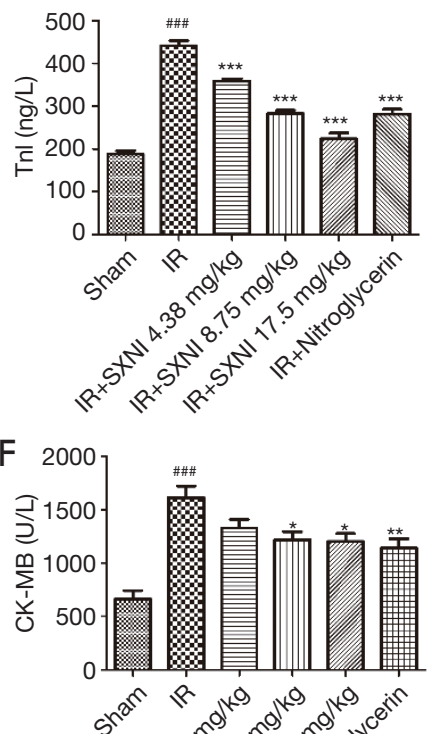

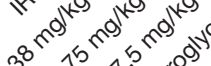

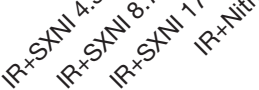

IR+SXNI $4.38 \mathrm{mg} / \mathrm{kg}$

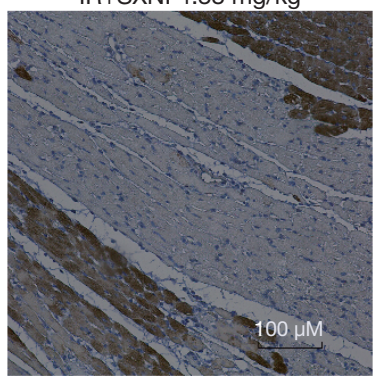

IR+Nitroglycerin

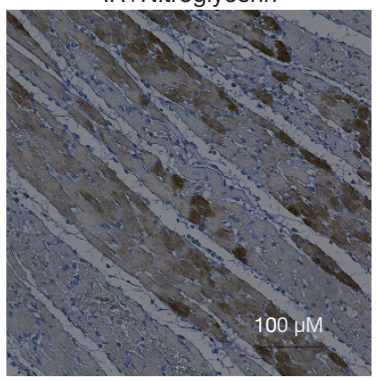

D
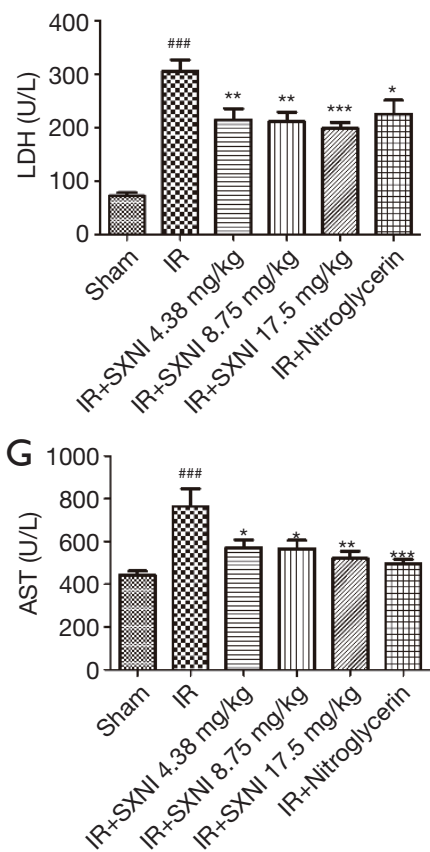

Figure 3 SXNI can reduce myocardial damage induced by MIRI. (A) Representative images of Tnl expressions in the rat ventricular myocardium determined by immunohistochemistry; (B) statistical results of immunohistochemistry; (C,D,E,F,G) the levels of CK, CK-MB, AST, LDH and Tnl were detected. Data are expressed as the means \pm SD from at least three independent experiments. ${ }^{\# \#}, \mathrm{P}<0.001$ vs. sham group; *, $\mathrm{P}<0.05$ vs. IR group; **, $\mathrm{P}<0.01$ vs. IR group; ${ }^{* * *}, \mathrm{P}<0.001$ vs. IR group. SXNI, Shuxuening injection; MIRI, myocardial ischemiareperfusion injury; CK, creatine kinase; AST, aspartate aminotransferase; LDH, lactate dehydrogenase. 

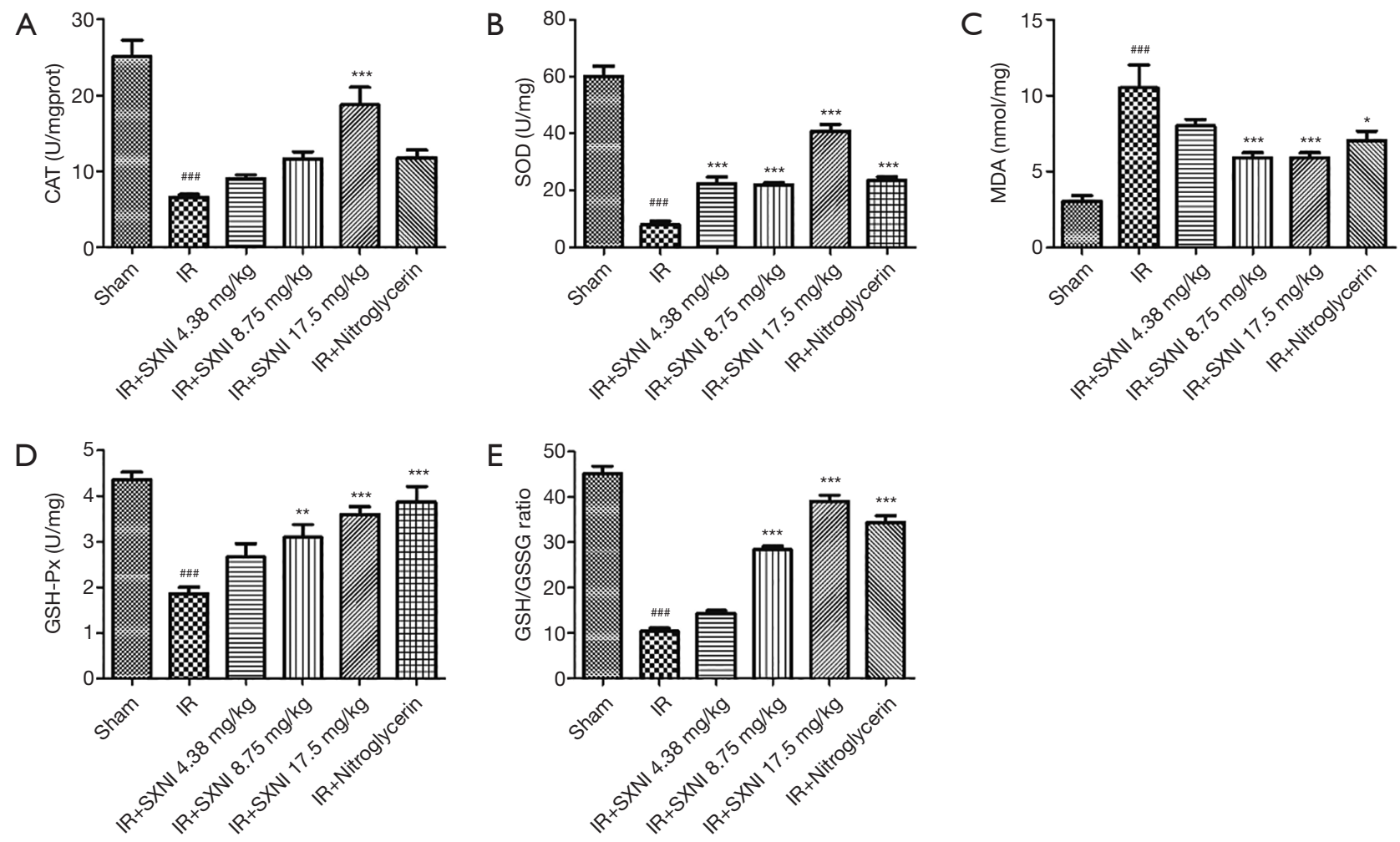

Figure 4 SXNI can exert cardioprotective effects by mitigating oxidative stress. (A,B,C,D,E) The levels of antioxidant enzymes (i.e., CAT, SOD and GSH-Px), GSH/GSSG ratio and MDA were measured. Data are expressed as the means \pm SD from at least three independent experiments. ${ }^{\# \# \#, ~} \mathrm{P}<0.001$ vs. sham group; *, $\mathrm{P}<0.05$ vs. IR group; ${ }^{* *}, \mathrm{P}<0.01$ vs. IR group; ***, $\mathrm{P}<0.001$ vs. IR group. SXNI, Shuxuening injection.

detected by western blot. The model group increased the expression of TLR 4 and nuclear factor kappa B $(\mathrm{NF}-\kappa \mathrm{B})(23)$ and SXNI+IR groups gradually restore the increased expression of TLR 4 and NF- $\mathrm{\kappa B}$ induced by MIRI, as showed in Figure 6B. The results proved that SXNI may play a cardioprotective role by reducing the inflammatory response related to TLR4/NF-кB.

\section{Effect of SXNI on platelet function}

Myocardial IR can cause endothelial damage which activates the blood clotting system, fibrinolytic system, vascular endothelium system and platelet system to participate in repair (24). We detected levels of various key factors including PAF, ET, PAI-1, TF, TXB2 and Fbg. Figure 1 showed that the levels of the six indicators (i.e., ET, PAF, PAI-1, TF, TXB2 and Fbg) increased much more than those of the other groups $(\mathrm{P}<0.01)$ as showed in Figure 7. SXNI could decrease the change of the plasma coagulation and plasmin system index $(\mathrm{P}<0.01)$.

\section{Discussion}

SXNI mainly contains G. biloba extract and have considerable clinical effect on coronary heart disease, unstable angina, cerebral infarction, atherosclerosis (10). This study focused on the protective effect of SXNI on MIRI. SXNI can significantly inhibit isoproterenol-induced myocardial ischemia in rats by significantly dilating blood vessels and increasing coronary flow $(8,9)$. Our experiment used coronary artery ligation to induce myocardial ischemia $30 \mathrm{~min}$ and then reperfusion for $24 \mathrm{~h}$. The results proved that SXNI can reduce the area of myocardial infarction and the degree of myocardial damage. Hence, the question on how does SXNI play a role in myocardial protection should be addressed. Flavonoid and ginkgolides are the two main active ingredients; flavonoid plays an excellent role in antioxidant effect, and ginkgolide has anti-platelet 
A

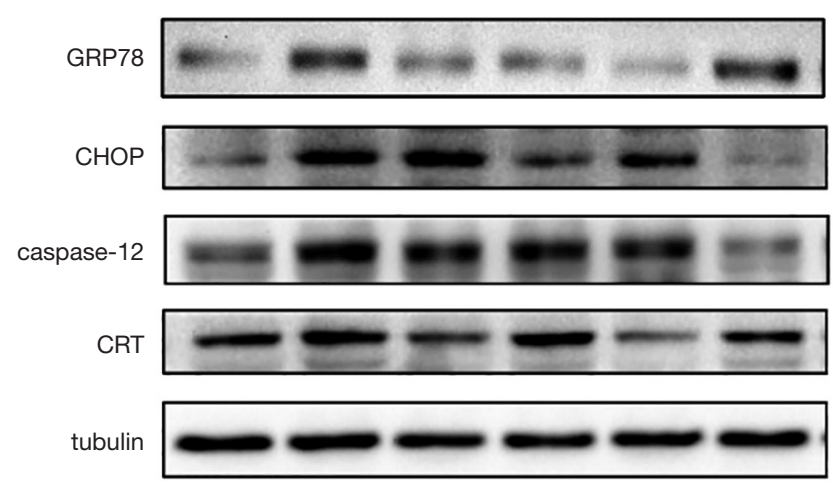

C

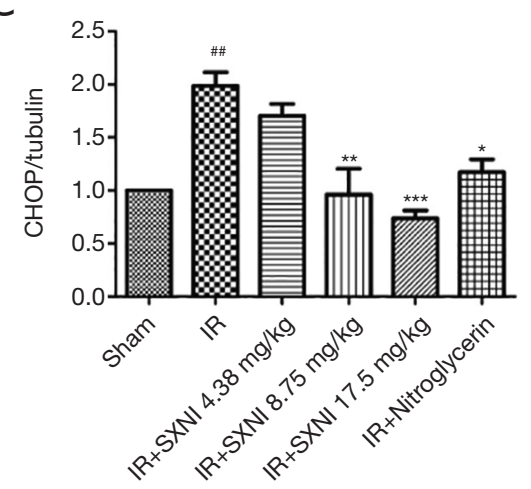

D

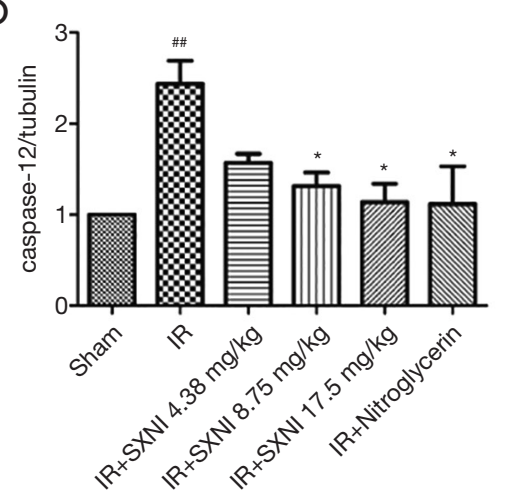

B

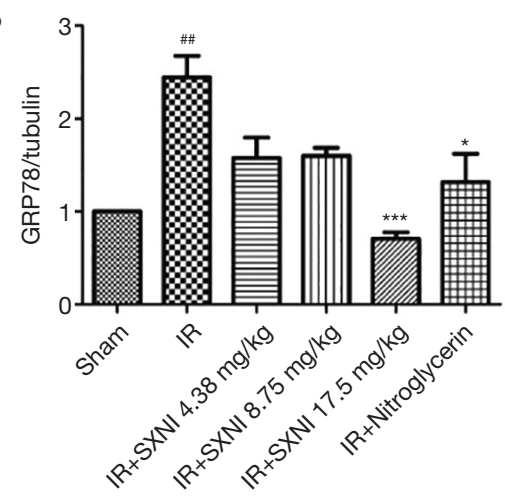

$\mathrm{E}$

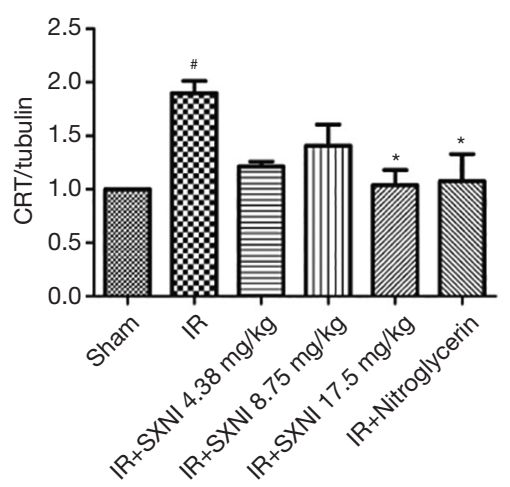

Figure 5 Effect of SXNI on ERS. (A) The expression levels of ERS markers GRP78- and ERS-related apoptotic pathway protein (i.e., CHOP, caspase-12 and CRT) was analyzed by western blot; (B,C,D,E) the relative protein expression of GRP78, CHOP, caspase-12 and CRT was expressed in the bar graphs. Data are expressed as the means \pm SD from at least three independent experiments. ", $\mathrm{P}<0.05$ vs. sham group; ${ }^{* \#}, \mathrm{P}<0.01$ vs. sham group; *, $\mathrm{P}<0.05$ vs. IR group; ${ }^{* *}, \mathrm{P}<0.01$ vs. IR group; ${ }^{* * *}, \mathrm{P}<0.001$ vs. IR group. SXNI, Shuxuening injection; ERS, endoplasmic reticulum stress; CRT, calreticulin.

aggregation effect $(25,26)$. However, the protective mechanism of SXNI on MIRI is still unclear. Therefore, our study specifically explored protective mechanism of SXNI from three aspects, namely oxidative stress, inflammatory response and platelet function.

The experimental and clinical studies demonstrated that oxidative stress is enhanced in MIRI. Oxidative stress can cause cardiomyocyte dysfunction, protein and lipid peroxidation and DNA damage, which finally develop into irreversible cell injury and death (27). Under physiological conditions, antioxidants protect cells from oxidative damage and scavenging free radicals by the antioxidase to maintain vasodilation (28). Serum MDA levels are a prominent marker of lipid peroxidation and generally identified as markers of free radical activity, which indirectly reflects the severity of free radical damage to tissues (29). Therefore, oxidative stress will occur during the imbalance of oxidant and antioxidant system caused by excessive generation of ROS or insufficient antioxidant mechanism (30). In this study, the antioxidant enzymes (i.e., GSH, CAT and SOD) and MDA levels were measured. SXNI can enhance the decrease in antioxidant enzyme activity induced by MIRI and decrease the MDA level.

Oxidative stress can activate ERS (13). ER is the main place of protein synthesis, folding and secretion. Under myocardial ischemia, excess ROS leads to ER dysfunction, thereby manifesting as the accumulation of unfolded and misfolded proteins. Thus, ERS is used to clear the wrong protein and repair damaged cells by increased GRP78 and CRT expression levels (22). However, persistent and severe ERS can activate CHOP and caspase-12, thereby eventually resulting in apoptosis $(31,32)$. In our experiment, the expression levels of ERS-related molecules, such as GRP78, CHOP, CRT and caspase-12, increased due to 
A
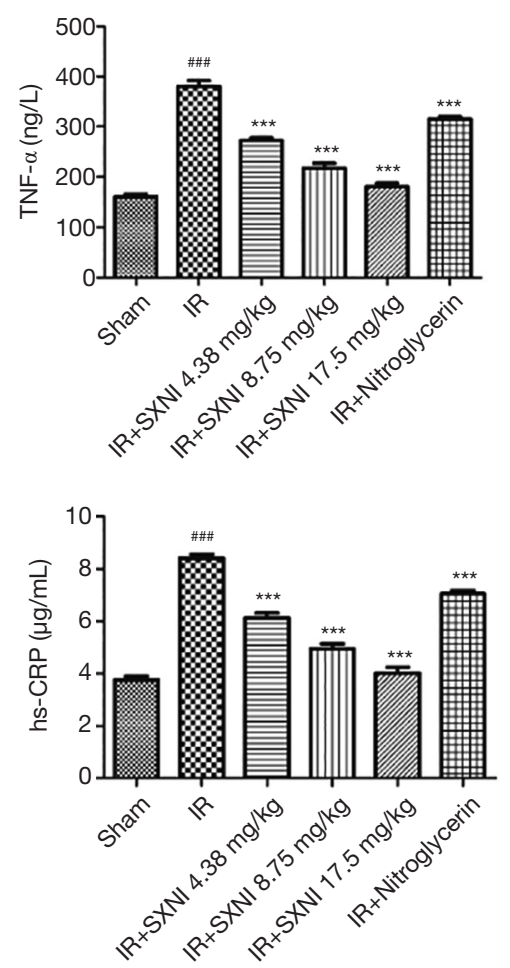

B

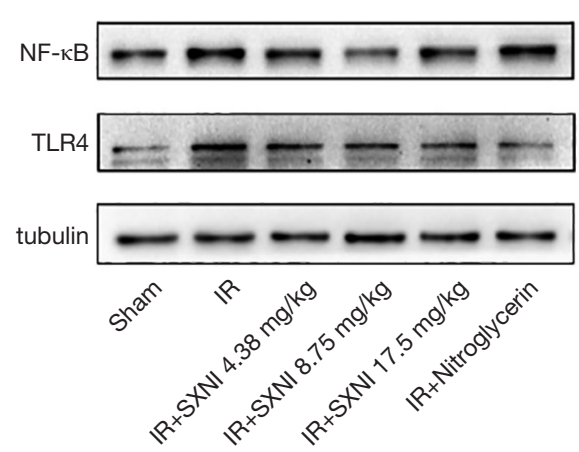

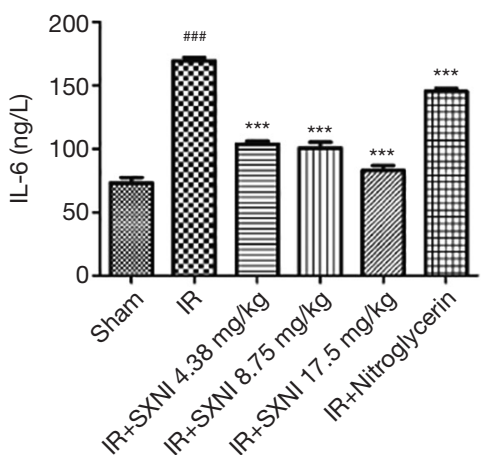
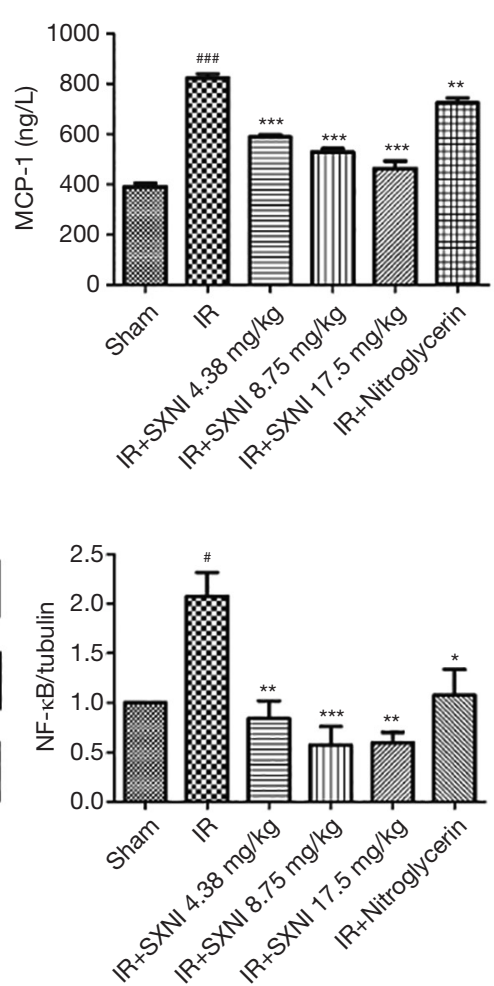
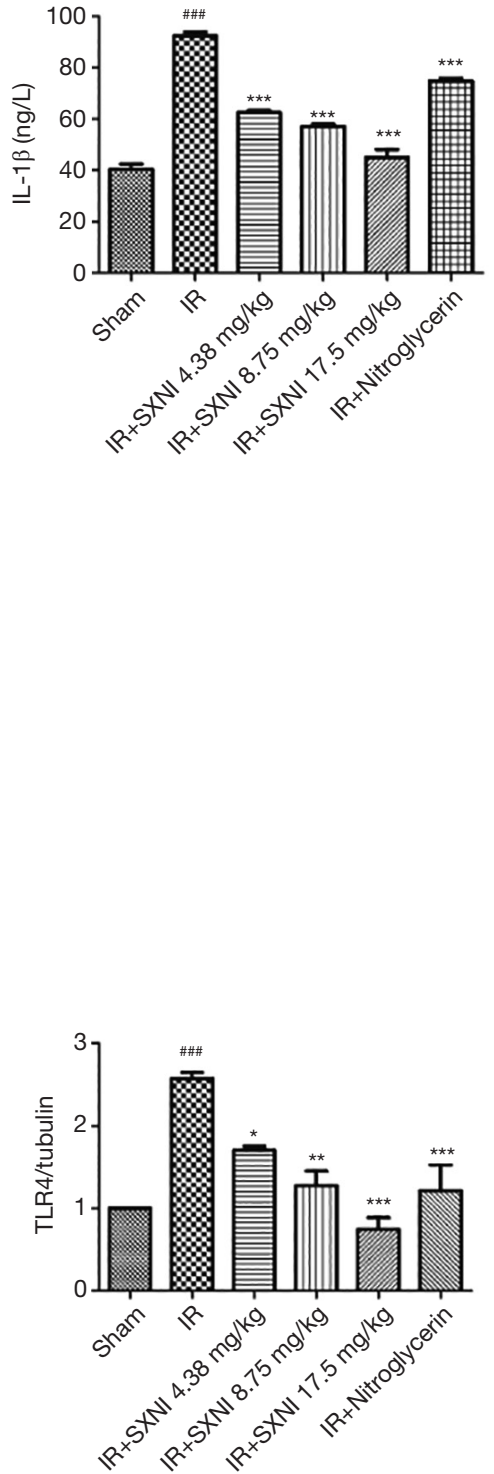

Figure 6 Effect of SXNI on inflammatory. (A) The inflammatory factors (i.e., TNF- $\alpha$, IL-6, IL-1 $\beta$, hs-CRP and MCP-1) levels were detected. (B) The TLR4 and NF- $\mathrm{KB}$ expression levels was analyzed by western blot. Data are expressed as the means \pm SD from at least three independent experiments. " , $\mathrm{P}<0.05$ vs. sham group; ${ }^{\# \#}, \mathrm{P}<0.001$ vs. sham group; *, $\mathrm{P}<0.05$ vs. IR group; **, $\mathrm{P}<0.01$ vs. IR group; $* * *, \mathrm{P}<0.001$ vs. IR group. SXNI, Shuxuening injection.

MIRI. However, SXNI could reduce the expression of these proteins, thereby reducing ERS and relieving heart damage. Therefore, SXNI can achieve myocardial protection by inhibiting oxidative stress and ERS.

Inflammation plays a key part in the progress of MIRI (33). Inflammatory factors can increase platelet adhesion, vascular endothelial damage, collagen exposure, and platelet activation (34). And a large amount of hs-
CRP release is prone to thrombosis, which accelerates the formation and instability of atheromatous plaques and is an important factor of clinical heart vascular events. TNF- $\alpha$ is an important inflammatory factor closely related to myocardial injury (35). The TNF- $\alpha$ level rapidly increases when myocardial IR injury occurs, promotes the adhesion and interaction of leukocytes and endothelial cells, and increases the infiltration of granulocytes into the 
A
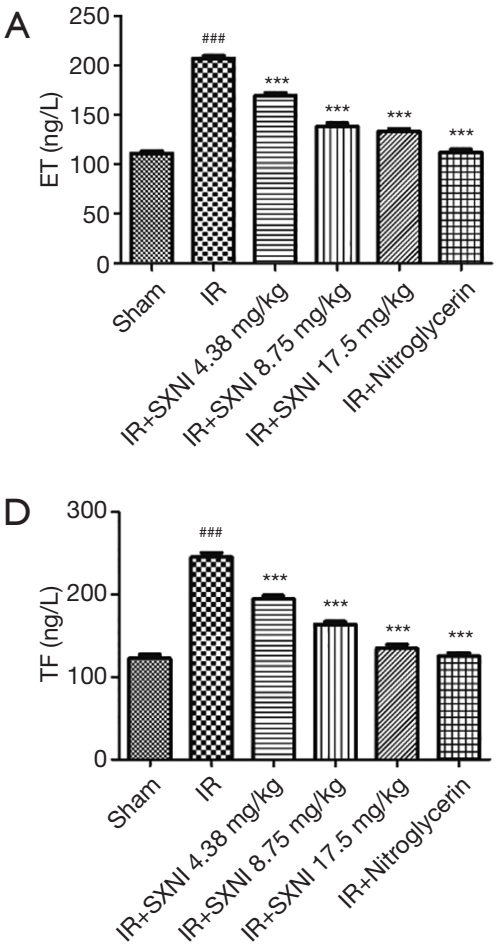

B

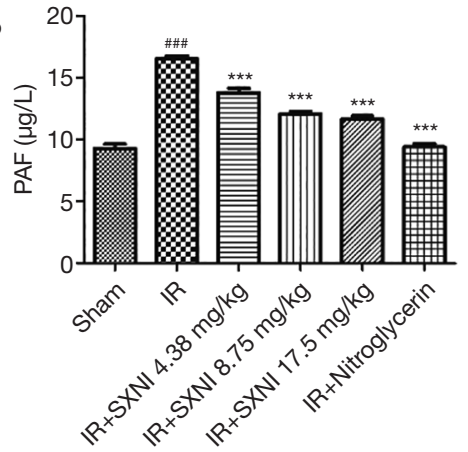

E

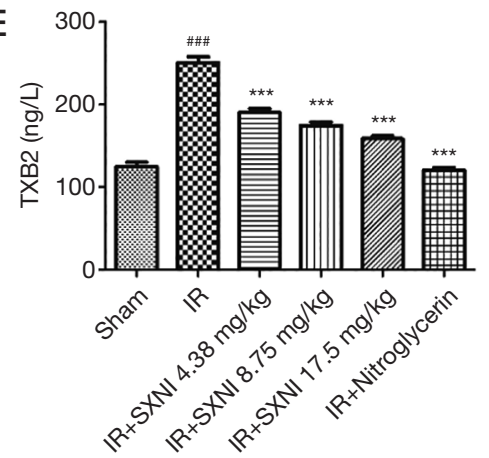

C

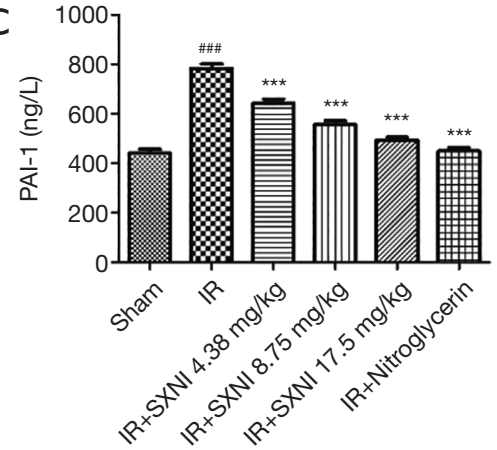

$\mathrm{F}$

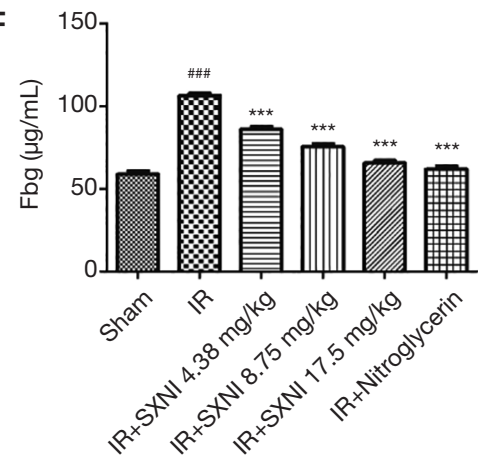

Figure 7 Effect of SXNI on platelet function. (A,B,C,D,E,F) The ET, PAF, PAI-1, TF, TXB2 and Fbg levels in plasma were measured. Data are expressed as the means $\pm \mathrm{SD}$ from at least three independent experiments. ${ }^{\# \#,}, \mathrm{P}<0.001 v s$. sham group; ${ }^{* * *}, \mathrm{P}<0.001$ vs. IR group. SXNI, Shuxuening injection; ET, endothelin; PAF, platelet activating factor; PAI-1, plasminogen activator inhibitor 1; TF, tissue factor; TXB2, thromboxane B2; Fbg, fibrinogen.

ischemic reperfusion area, which induces to myocardial dysfunction increase $(36,37)$. IL- 6 and IL- $1 \beta$ are the proinflammatory factors mainly from the coronary vascular endothelium which aggravates myocardial damage by promoting endothelial cell and neutrophil adhesion $(34,38)$. The hs-CRP levels are closely related to the occurrence, severity and prognosis of atherosclerosis and acute cerebral infarction, and are one of the most effective predictors of cardiovascular events. MCP-1 is also one of the monocytokines that independently predicts coronary heart disease which activates monocyte/macrophage migration, aggregates them under the intima of the blood vessels and inhibits its random movement and chemotaxis, after being activated as a macrophage (39). In this study, we investigated the levels of inflammatory factors in rat serum. Our results indicate that the MIRI model group significantly increases the inflammatory factors levels, and SXNI can be dosedependently restored their increase induced by MIRI. This result proved that SXNI reduced myocardial damage by balancing pro-inflammatory and anti-inflammatory factors.
The TLR4 and NF-kB expression levels in rat arterial tissues were also examined. TLR4 is a transmembrane receptor that mediates inflammation and innate immune response. When TLR4 binds to ligand, it can activate $\mathrm{NF}-\kappa \mathrm{B}$ and regulate the expression of inflammation related genes $(23,33,40)$. SXNI can reduce the expression of TLR4 and NF- $\kappa B$ pathway. Therefore, the protective effect of SXNI on the heart is related to inhibiting inflammatory response.

Platelet activation is non-negligible in patients with coronary heart disease (41). Persistent platelet activation is associated with thrombosis. PAF is the strongest platelet aggregation inducer discovered thus far, and involved in activating platelet, mediating inflammatory response and free radical production, and damaging vascular endothelial cells. PAF has both pro-inflammatory and thrombogenic properties and promote a key role in thrombosis. Ginkgolide is a well-recognized PAF receptor antagonist, and its pharmacological action against PAF has been confirmed (42). Our results showed that the PAF level in 
SXNI groups significantly decreased, thereby suggesting that SXNI can block platelet aggregation activated by PAF pathway.

In the pathogenesis and development of acute myocardial ischemia, blood flow is blocked to activate coagulation factors and platelets, and vascular endothelial cells have a stress response which promotes the conversion of Fbg to fibrin (35). After that, the dynamic balance of the body's coagulation and fibrinolysis system is destroyed, the fibrinolytic activity is decreased, and the coagulation is dominant, which is conducive to the formation of thrombus on the blood vessel wall by fibrin deposition. The results lead to an enlargement of the acute myocardial infarction area, therefore further aggravating the condition. TF is the initiator of the exogenous coagulation process. Under normal conditions, TF is not present in the circulation or in contact with circulating blood. Only when the integrity of the vessel wall is destroyed, the collagen fibers are exposed into the blood, and then TF is released in the circulating blood by the tissue cells. So, the blood coagulation reaction is initiated by the exogenous coagulation pathway. t-PA and PAI-1 are important active substances in the fibrinolytic system (43). The role of t-PA is to activate plasminogen to make it active plasmin, so as to eliminate blood clots in time, or directly acting on fibrinolytic protein to enhance fibrinolytic effect (44). PAI-1 acts to inactivate t-PA and increase thrombus formation at ischemic site.

Vascular regulatory factors secreted by vascular endothelial cells play an important role in the formation of thrombus, and ET and NO play an important role in regulating contraction and relaxation of blood vessels and the formation of thrombosis (45). ET has a strong role in promoting endothelial cell proliferation and blood vessels contraction, and can also induce myocardial ischemia and remodeling by promoting vascular smooth muscle cell activation and proliferation $(6,46)$. NO has the effect of relaxing vascular smooth muscle, and inhibiting thrombus formation and endothelial cell proliferation. Under normal conditions, the NO and ET levels in the plasma of the body are in a dynamic equilibrium, and the two factors can influence and regulate each other (47). If the balance is broken, a series of pathophysiological changes will be caused. Platelet dysfunction is also one of the causes of myocardial ischemia. TXA2 is a platelet-inducing agent and a vasoconstrictor, while PGI2 is a platelet aggregation inhibitor and a vasodilator. Generally, TXA2 and PGI2 which constitute an important factor in maintaining blood circulation are in dynamic balance in the body. When
TXA2 and PGI2 are unbalanced, thrombus formation can occur which aggravates a series of changes in tissue damage (24). TXA2 and PGI2 are extremely unstable in vivo and rapidly degraded into inactive and stable TXB2 in a short time. Therefore, the TXB2 content determination can indirectly reflect the TXA2 and PGI2 levels in vivo (48). In this experiment, the ET, PAI-1, TF, TXB2 and Fbg levels were significantly increased compared with the model group, and SXNI can significantly reduce the increase in various indexes caused by the model group and restore the balance of plasma coagulation and plasmin system.

Oxidative stress makes a huge difference in thrombosis. Under normal physiological conditions, antioxidants protect the cells from oxidative stress and can be removed by free radicals to maintain vasodilation (27). Excessive ROS can reduce the $\mathrm{NO}$ and $\mathrm{PGI}_{2}$ content and increase the production of vasoconstrictors such as ET-1 and TXA2 (48), resulting in vascular diastolic dysfunction. SOD is an antioxidant that not only serves as a free radical remover but also improves thrombolytic factors, such as t-PA (49). Therefore, during myocardial ischemia and hypoxia, the level of ROS increases dramatically, oxidative stress will promote the formation of thrombus when ROS exceeds the body's antioxidant defense. Oxidative stress is closely related to inflammation. ROS production can stimulate $\mathrm{NF}-\kappa \mathrm{B}$, and then induce the expression of inflammatory factors such as TNF- $\alpha, \mathrm{IL}-1 \beta$, IL-6 (50). Myocardial ischemia and hypoxia cause impaired mitochondrial function and neutrophils activation, thereby resulting in a significant increase in oxygen radicals. Thus, the chain reaction between oxidation and inflammation is further strengthened. Inflammatory factors, such as TNF $\alpha$, IL-6 and IL-1, are not only signal transduction molecules but also effector molecules, they can directly stimulate vascular endothelial cells, thereby leading to vascular endothelial cells damage and increasing its permeability (51). This also results that thrombin and adrenaline induce and release PAF which promotes platelet activation, aggregation, adhesion, and finally thrombosis. Thus, oxidative stress promotes inflammatory responses and thrombosis, while inflammation induces oxidative stress and endothelial dysfunction (52).

In conclusion, SXNI can reduce myocardial infarct size caused by ligating left anterior descending of the coronary artery, reduce myocardial enzyme levels, and improve myocardial pathological damage. The mechanism of myocardial protection of SXNI is closely related to maintain the balance of oxidation and antioxidant system, 
reduce oxidative stress and ERS damage, inhibit excessive inflammatory factor response, improve platelet function, and inhibit thrombosis. However, the current research on the specific relationship among oxidative stress, inflammation and platelet function is still not deep enough, and further exploration is needed to understand the specific mechanism of SXNI heart protection.

\section{Acknowledgments}

Funding: This study was supported by CAMS Innovation Fund for Medical Sciences (Grant No. 2016-I2M-1-012), Central Public-Interest Scientific Institution Basal Research Fund (Grant No. 2018PT35030) and the Drug Innovation Major Project (Grant No. 2018ZX09711-001-009).

\section{Footnote}

Conflicts of Interest: The authors declare that the research was conducted in the absence of any commercial or financial relationships that could be construed as a potential conflict of interest.

Ethical Statement: The study was approved by the Institutional Animal Care and Use Committee of Chinese Academy of Medical Sciences and Peking Union Medical College (SYXK 2017-0020). The authors are accountable for all aspects of the work in ensuring that questions related to the accuracy or integrity of any part of the work are appropriately investigated and resolved.

\section{References}

1. Li S, Cao C, Chen H, et al. Atheroprotective effects of statins in patients with unstable angina by regulating the blood-borne microRNA network. Mol Med Rep 2017;16:817-27.

2. Heusch G, Musiolik J, Gedik N, et al. Mitochondrial STAT3 activation and cardioprotection by ischemic postconditioning in pigs with regional myocardial ischemia/reperfusion. Circ Res 2011;109:1302-8.

3. Zhu S, Xu T, Luo Y, et al. Luteolin Enhances Sarcoplasmic Reticulum Ca2+-ATPase Activity through p38 MAPK Signaling thus Improving Rat Cardiac Function after Ischemia/Reperfusion. Cell Physiol Biochem 2017;41:999-1010.

4. Wang C, Liu N, Luan R, et al. Apelin protects sarcoplasmic reticulum function and cardiac performance in ischaemia-reperfusion by attenuating oxidation of sarcoplasmic reticulum Ca2+-ATPase and ryanodine receptor. Cardiovasc Res 2013;100:114-24.

5. Okonko DO, Shah AM. Heart failure: mitochondrial dysfunction and oxidative stress in CHF. Nat Rev Cardiol 2015;12:6-8.

6. Wang ZY, Zhang W, Li XZ, et al. CPU0213, a novel endothelin type $\mathrm{A}$ and type $\mathrm{B}$ receptor antagonist, protects against myocardial ischemia/reperfusion injury in rats. Braz J Med Biol Res 2011;44:1148-55.

7. Mueller C, Neumann F, Hochholzer W, et al. The impact of platelet count on mortality in unstable angina/nonST-segment elevation myocardial infarction. Am Heart J 2006;151:1214.e1-7.

8. Feng H, Chen X, Li C, et al. Combined common femoral artery endarterectomy with superficial femoral artery stenting plus Shuxuening Injection infusion for chronic lower extremity ischemia: 3-year results. Chin J Integr Med 2012;18:417-22.

9. Lyu M, Cui Y, Zhao T, et al. Tnfrsf12a-Mediated Atherosclerosis Signaling and Inflammatory Response as a Common Protection Mechanism of Shuxuening Injection Against Both Myocardial and Cerebral IschemiaReperfusion Injuries. Front Pharmacol 2018;9:312.

10. Wang C, Shi Q, Ding F, et al. Reevaluation of the postmarketing safety of Shuxuening injection based on realworld and evidence-based evaluations. Drug Des Devel Ther 2018;12:757-67.

11. Jiang WY. Therapeutic wisdom in traditional Chinese medicine: a perspective from modern science. Trends Pharmacol Sci 2005;26:558-63.

12. Wang M, Chen L, Liu D, et al. Metabolomics highlights pharmacological bioactivity and biochemical mechanism of traditional Chinese medicine. Chem-Biol Interact 2017;273:133-41.

13. Jin JK, Blackwood E, Azizi K, et al. ATF6 Decreases Myocardial Ischemia/Reperfusion Damage and Links ER Stress and Oxidative Stress Signaling Pathways in the Heart. Circ Res 2017;120:862-75.

14. Yang J, Yang C, Yang J, et al. RP105 alleviates myocardial ischemia reperfusion injury via inhibiting TLR4/TRIF signaling pathways. Int J Mol Med 2018;41:3287-95.

15. Wang EW, Han YY, Jia XS. PAFR-deficiency alleviates myocardial ischemia/reperfusion injury in mice via suppressing inflammation, oxidative stress and apoptosis. Biochem Biophys Res Commun 2018;495:2475-81.

16. Du Y, Wang M, Liu X, et al. Araloside C Prevents Hypoxia/Reoxygenation-Induced Endoplasmic Reticulum 
Stress via Increasing Heat Shock Protein 90 in H9c2 Cardiomyocytes. Front Pharmacol 2018;9:180.

17. Yu Y, Sun G, Luo Y, et al. Cardioprotective effects of Notoginsenoside R1 against ischemia/reperfusion injuries by regulating oxidative stress- and endoplasmic reticulum stress- related signaling pathways. Sci Rep 2016;6:21730.

18. Luan Y, Sun C, Wang J, et al. Baicalin attenuates myocardial ischemia-reperfusion injury through Akt/NFkappaB pathway. J Cell Biochem 2019;120:3212-9.

19. Yu Z, Wang $S$, Zhang $X$, et al. Pterostilbene protects against myocardial ischemia/reperfusion injury via suppressing oxidative/nitrative stress and inflammatory response. Int Immunopharmacol 2017;43:7-15.

20. Yang $M$, Chen J, Zhao J, et al. Etanercept Attenuates Myocardial Ischemia/Reperfusion Injury by Decreasing Inflammation and Oxidative Stress. Plos One 2014;9:e108024.

21. Marí M, Morales A, Colell A, et al. Mitochondrial Glutathione, a Key Survival Antioxidant. Antioxid Redox Signal 2009;11:2685-700.

22. Fang SJ, Li PY, Wang CM, et al. Inhibition of endoplasmic reticulum stress by neuregulin-1 protects against myocardial ischemia/reperfusion injury. Peptides 2017;88:196-207.

23. Pan YQ, Li J, Li XW, et al. Effect of miR-21 TLR4 NF- $\mathrm{KB}$ pathway on myocardial apoptosis in rats with myocardial ischemia-reperfusion. Eur Rev Med Pharmacol Sci 2018;22:7928-37.

24. Prakash P, Misra A, Surin W, et al. Anti-platelet effects of Curcuma oil in experimental models of myocardial ischemia-reperfusion and thrombosis. Thromb Res 2011;127:111-8.

25. Wang Q, Sui X, Sui D, et al. Flavonoid Extract from Propolis Inhibits Cardiac Fibrosis Triggered by Myocardial Infarction through Upregulation of SIRT1. Evid Based Complement Alternat Med 2018;2018:4957573.

26. Zhao X, Yao H, Yin H, et al. Ginkgo biloba Extract and Ginkgolide Antiarrhythmic Potential by Targeting hERG and ICa-L Channel. J Pharmacol Sci 2013;123:318-27.

27. Yang X, Li Y, Li Y, et al. Oxidative Stress-Mediated Atherosclerosis: Mechanisms and Therapies. Front Physiol 2017;8:600.

28. Sies H, Berndt C, Jones DP. Oxidative Stress. Annu Rev Biochem 2017;86:715-48.

29. Liu XW, Lu MK, Zhong HT, et al. Panax Notoginseng Saponins Attenuate Myocardial Ischemia-Reperfusion Injury Through the HIF-1 $\alpha$ BNIP3 Pathway of Autophagy. J Cardiovasc Pharmacol 2019;73:92-9.
30. Al-Salam S, Hashmi S. Myocardial Ischemia Reperfusion Injury: Apoptotic, Inflammatory and Oxidative Stress Role of Galectin-3. Cell Physiol Biochem 2018;50:1123-39.

31. Guo C, Zhang J, Zhang P, et al. Ginkgolide B ameliorates myocardial ischemia reperfusion injury in rats via inhibiting endoplasmic reticulum stress. Drug Des Devel Ther 2019;13:767-74.

32. Misaka T, Murakawa T, Nishida K, et al. FKBP8 protects the heart from hemodynamic stress by preventing the accumulation of misfolded proteins and endoplasmic reticulum-associated apoptosis in mice. J Mol Cell Cardiol 2018;114:93-104.

33. Ma C, Jiang $\mathrm{Y}$, Zhang $\mathrm{X}$, et al. Isoquercetin ameliorates myocardial infarction through anti-inflammation and antiapoptosis factor and regulating TLR4-NF-kappaB signal pathway. Mol Med Rep 2018;17:6675-80.

34. Damås JK, Waehre T, Yndestad A, et al. Interleukin-7mediated inflammation in unstable angina: possible role of chemokines and platelets. Circulation 2003;107:2670-6.

35. Jia P, Wang J, Wang L, et al. TNF- $\alpha$ Upregulates Fgl2 Expression in Rat Myocardial Ischemia/Reperfusion Injury. Microcirculation 2013;20,524-33.

36. Huang XW, Pan MD, Du PH, et al. Arginase-2 protects myocardial ischemia-reperfusion injury via NF- $\mathrm{kB} / \mathrm{TNF}-\alpha$ pathway. Eur Rev Med Pharmacol Sci 2018;22:6529-37.

37. Badalzadeh R, Baradaran B, Alihemmati A, et al. Troxerutin Preconditioning and Ischemic Postconditioning Modulate Inflammatory Response after Myocardial Ischemia/Reperfusion Injury in Rat Model. Inflammation 2017;40:136-43.

38. Meng Y, Liu Y, Hu Z, et al. Sanguinarine Attenuates Lipopolysaccharide-induced Inflammation and Apoptosis by Inhibiting the TLR4/NF-kappaB Pathway in H9c2 Cardiomyocytes. Curr med sci 2018;38:204-11.

39. Yi Q, Tan F, Tan J, et al. Minocycline protects against myocardial ischemia/reperfusion injury in rats by upregulating MCPIP1 to inhibit NF-kappaB activation. Acta pharmacol Sin 2019;40:1019-28.

40. Sherif IO, Al-Shaalan NH. Vildagliptin Attenuates Hepatic Ischemia/Reperfusion Injury via the TLR4/ NF-kappaB Signaling Pathway. Oxid med cell longev 2018;2018:3509091.

41. Hung YC, Kuo YJ, Huang SS, et al. Trimucrin, an ArgGly-Asp containing disintegrin, attenuates myocardial ischemia-reperfusion injury in murine by inhibiting platelet function. Eur J Pharmacol 2017;813:24-32.

42. Doukas J, Wrasidlo W, Noronha G, et al. Phosphoinositide 3-kinase gamma/delta inhibition limits infarct size after 
myocardial ischemia/reperfusion injury. Proc Nati Acad Sci USA 2006;103:19866-71.

43. Vilahur G, Ben-Aicha S, Badimon L. New insights into the role of adipose tissue in thrombosis. Cardiovasc Res 2017;113:1046-54.

44. Loubele ST, Spek CA, Leenders P, et al. Activated Protein C Protects Against Myocardial Ischemia/Reperfusion Injury via Inhibition of Apoptosis and Inflammation. Arterioscler Thromb Vasc Biol 2009;29:1087-92.

45. Chen C, Chen W, Nong Z, et al. Cardioprotective Effects of Combined Therapy with Hyperbaric Oxygen and Diltiazem Pretreatment on Myocardial IschemiaReperfusion Injury in Rats. Cell Physiol Biochem 2016;38:2015-29.

46. Shi Y, Han B, Yu X, et al. Ginsenoside Rb3 ameliorates myocardial ischemia-reperfusion injury in rats. Pharm Biol 2011;49:900-6.

47. Cao L, Huang C, Wang N, et al. ET-1/NO: A

Controversial Target for Myocardial Ischemia-Reperfusion
Injury. Cardiology 2014;127:140.

48. Guo X, Cao W, Yao J, et al. Cardioprotective effects of tilianin in rat myocardial ischemia-reperfusion injury. Mol Med Rep 2015;11:2227-33.

49. Zhao YB, Wang YZ, Yue YH, et al. Variation of plasma levels of endothelin, calcitonin gene-related peptide, nitric oxide, and malondialdehyde in acute myocardial ischemia reperfusion injury in a rabbit model. Genet Mol Res 2015;14:5577-84.

50. Pashkow FJ. Oxidative Stress and Inflammation in Heart Disease: Do Antioxidants Have a Role in Treatment and/ or Prevention? Int J Inflam 2011;2011:514623.

51. Sloop GD, Weidman JJ, St Cyr JA. Atherothrombosis is a Thrombotic, not Inflammatory Disease. Cureus 2017;9:e1909.

52. Capra V, Bäck M, Angiolillo D, et al. Impact of vascular thromboxane prostanoid receptor activation on hemostasis, thrombosis, oxidative stress, and inflammation. J Thromb Haemost 2014;12:126-37.
Cite this article as: Wang R, Wang M, Zhou J, Ye T, Xie X, Ni D, Ye J, Han Q, Di C, Guo L, Sun G, Sun X. Shuxuening injection protects against myocardial ischemia-reperfusion injury through reducing oxidative stress, inflammation and thrombosis. Ann Transl Med 2019;7(20):562. doi: 10.21037/ atm.2019.09.40 